\title{
Experimental access to elastic and thermodynamic properties of $\mathrm{RbMnFe}(\mathrm{CN})_{6}$
}

\author{
K. Boukheddaden, ${ }^{1, a)}$ E. D. Loutete-Danguii, ${ }^{1}$ E. Codjovi, ${ }^{1}$ M. Castro, ${ }^{2}$ \\ J. A. Rodriguéz-Velamazán, ${ }^{2}$ S. Ohkoshi, ${ }^{3}$ H. Tokoro, ${ }^{3}$ M. Koubaa, ${ }^{1,4}$ Y. Abid, ${ }^{4}$ and \\ F. Varret ${ }^{1}$ \\ ${ }^{1}$ CNRS-Université de Versailles/St. Quentin en Yvelines, 45 Avenue des Etats Unis, \\ F78035 Versailles Cedex, France \\ ${ }^{2}$ Instituto de Ciencia de Materiales de Aragón, CSIC-Universidad de Zaragoza, Pedro Cerbuna 12, \\ 50009 Zaragoza, Spain \\ ${ }^{3}$ Department of Chemistry, School of Science, The University of Tokyo, 7-3-1 Hongo, Bunkyo-ku, \\ Tokyo 113-0033, Japan \\ ${ }^{4}$ Laboratoire de Physique Appliquée (LPA), Faculté des Sciences de Sfax, University of Sfax, 3018 BP 802, \\ Tunisia
}

(Received 22 July 2010; accepted 17 November 2010; published online 11 January 2011)

\begin{abstract}
We use spectroscopic ellipsometry to study the elastic and thermodynamic properties of the structural first-order transition of the cooperative Jahn-Teller solid, $\operatorname{RbMn}\left[\mathrm{Fe}(\mathrm{CN})_{6}\right]$. While the analysis of the thermal dependence of the dielectric constant revealed a remarkable energy shift in the metal-to-ligand charge transfer band, that of the refractive index allowed to evaluate the volumetric thermal expansion coefficient in the two phases through the Gladstone-Dale relation. The access to the elastic properties of the solid is obtained with the reflectivity under pressure measurements, from which we estimated the bulk modulus values in the low- and high-temperature phases as $B_{\mathrm{LT}}=30( \pm 3) \mathrm{GPa}$ and $B_{\mathrm{HT}}=23( \pm 2) \mathrm{GPa}$, respectively. Assuming the system is isotropic, the corresponding Debye temperature values have been found to be $\theta_{D}^{\mathrm{LT}}(\mathrm{SE})$ $\simeq 360( \pm 25) \mathrm{K}$ and $\theta_{D}^{\mathrm{HT}}(\mathrm{SE}) \simeq 290( \pm 20) \mathrm{K}$, in good agreement with those derived from independent Mössbauer spectrometry investigations which led to $\theta_{D}^{\mathrm{LT}}(\operatorname{Moss}) \simeq 332( \pm 7) \mathrm{K}$ and $\theta_{D}^{\mathrm{HT}}($ Moss $) \simeq 280( \pm 11) \mathrm{K}$. Moreover, we have been able to extract from the SE data, the entropy change at the transition, $\Delta S \approx 64 \mathrm{~J} \mathrm{~K}^{-1} \mathrm{~mol}^{-1}$, which has been also found in good agreement with the value, $\Delta S \approx 60 \pm 5 \mathrm{~J} \mathrm{~K}^{-1} \mathrm{~mol}^{-1}$, derived from calorimetric experiments performed in this work. (C) 2011 American Institute of Physics. [doi:10.1063/1.3528239]
\end{abstract}

\section{INTRODUCTION}

Switchable molecular solids like spin-crossover (SC) (Ref. 1) and charge transfer Prussian Blue analogs (PBAs) (Refs. 2 and 3) exhibiting thermally-induced and photoinduced hysteresis are promising materials in terms of optical data storage, as static memories, ${ }^{4}$ sensors, ${ }^{5}$ displays, ${ }^{6}$ and switches. ${ }^{7}$ Among the PBAs, $\operatorname{RbMn}\left[\mathrm{Fe}(\mathrm{CN})_{6}\right]$ (Refs. 8-18) undergoes a first-order structural phase transition ${ }^{8}$ from the tetragonal $\left(\mathrm{D}_{4 \mathrm{~h}}\right)$ to the cubic $\left(\mathrm{O}_{\mathrm{h}}\right)$ phase. This structural phase transition involves a cooperative charge transfer between Mn and Fe, coupled with a Jahn-Teller (JT) distortion of the Mn ion, ${ }^{19-22}$ leading to a relative volume increase of $\sim 10 \%$ (Ref. 19) at the transition on heating. More precisely, the low temperature (LT) phase is $\mathrm{Mn}^{\mathrm{III}}-\mathrm{Fe}^{\mathrm{II}}$, where $\mathrm{Mn}^{\mathrm{III}}$ is high-spin (HS), $\left(d^{4}, S=2\right)$ and $\mathrm{Fe}^{\mathrm{II}}$ is low-spin (LS), $\left(d^{6}, \mathrm{~S}\right.$ $=0$ ), while the high temperature (HT) phase is $\mathrm{Mn}^{\mathrm{II}}-\mathrm{Fe}^{\mathrm{III}}$, where $\mathrm{Mn}^{\mathrm{II}}$ is $\mathrm{HS}\left(d^{5}, S=5 / 2\right)$ and $\mathrm{Fe}^{\mathrm{III}}$ is $\operatorname{LS}\left(d^{5}, S=1 / 2\right)$. We found that the LT and HT phases present enough difference in the electronic properties to be evidenced by spectroscopic ellipsometry (SE). Quite recently, Ohkoshi et al. ${ }^{23}$ and Loutete et al. ${ }^{24-26}$ have shown the ability of SE in the char-

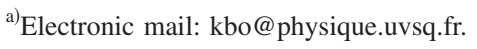

acterization of switchable materials. In particular SE was successfully applied to investigate the thermal dependence of the HS fraction in the SC compound $\left[\mathrm{Fe}\left(\mathrm{NH}_{2} \text {-trz }\right)_{3}\right] \mathrm{Br}_{2}$ (Ref. 24) leading to derive the thermal hysteresis loop of the sample, in good agreement with magnetic data. In addition, we previously reported on the application of the SE on the thermally induced charge transfer transition of $\mathrm{RbMn}\left[\mathrm{Fe}(\mathrm{CN})_{6}\right]^{25,26}$ In this previous work, we discussed the shape of the ellipsometric spectra (fitted using the LorentzGauss model), and assigned the various optical contributions, which were found to be related to the metal to ligand charge transfer, of $\mathrm{Fe}^{2+}(\mathrm{CN})_{6}$, intervalence (IT) charge transfer and $d-d$ JT transition of $\mathrm{Mn}^{3+}$. We also derived the thermal dependence of the HT fraction and found it in agreement with magnetic data. Here, we show that SE can also provide informations on the elastic properties of the material, such as bulk modulus, sound velocity and Debye temperature. To check the consistency of our results, additional investigations based on reflectivity under pressure, calorimetry, and Mössbauer spectrometry measurements were performed. The manuscript is organized as follows: Sec. II is devoted to the brief presentation of the various experimental setups used in this work; in Sec. III we show and discuss the obtained ex- 
perimental data from which we derive the elastic properties of the material. Section IV is devoted to the conclusions.

\section{EXPERIMENTAL SECTION}

The compound $\mathrm{RbMn}\left[\mathrm{Fe}(\mathrm{CN})_{6}\right]$ was prepared as in previous works ${ }^{27}$ using an aqueous solution of $\mathrm{MnCl}_{2}$ which was reacted with a mixed aqueous solution of $\mathrm{RbCl}$ and $\mathrm{K}_{3}\left[\mathrm{Fe}(\mathrm{CN})_{6}\right]$. The mixed solution was then stirred at room temperature, and the precipitate was filtered. A dark brown powder was obtained. Elemental analysis for $\mathrm{Rb}, \mathrm{Mn}$, and $\mathrm{Fe}$ was performed using an HP4500 inductively coupled plasma mass spectrometer, and those for $\mathrm{C}, \mathrm{H}, \mathrm{N}$, using standard microanalytical methods. Elemental analysis of the present sample showed that the formula was $\mathrm{Rb}_{0.94} \mathrm{Mn}\left[\mathrm{Fe}(\mathrm{CN})_{6}\right]_{0.98} \cdot 0.2 \mathrm{H}_{2} \mathrm{O}$.

$\mathrm{SE}$ was performed on pellets of $\mathrm{Rb}_{0.94} \mathrm{Mn}\left[\mathrm{Fe}(\mathrm{CN})_{6}\right]_{0.98} \cdot 0.2 \mathrm{H}_{2} \mathrm{O}$ of diameter $5 \mathrm{~mm}$ and thickness $1 \mathrm{~mm}$, obtained by pressing the powder under $10 \mathrm{kbar}$ for $3 \mathrm{~min}$, using an optical polished piston. The measurements were performed in the $240-1000 \mathrm{~nm}$ optical range at incident angle of $70^{\circ}$ (near the Brewster's angle), using the UVISEL spectroscopic phase modulated ellipsometer (Refs. 28 and 29) in which the light source was a $150 \mathrm{~W}$ Xe short arc lamp. The diameter of the light spot on the sample was of $\approx 3-4 \mathrm{~mm}$. Temperature control was realized by a Linkam TMS 94 controller with a platinum resistor as a temperature probe, with an accuracy of $\approx 0.1 \mathrm{~K}$. Recording time at each temperature was $3 \mathrm{~min}$.

$\mathrm{C}$-magnetization under $0.1 \mathrm{~T}$ applied field was measured by a superconducting quantum interference device magnetometer (Quantum Design MPMS-5), and the magnetic signal was corrected for the systematic contribution of the diamagnetic sample holder.

The Mössbauer spectra were recorded on a constantacceleration spectrometer, with a $50 \mathrm{mCi}$ source of ${ }^{57} \mathrm{Co}$ in rhodium matrix. The polycrystalline absorber contained 20 $\mathrm{mg}$ of material per centimeter square, and the spectra were fitted without correction of the thickness effect.

Calorimetric measurements were performed using a differential scanning calorimeter (DSC) Q1000 from TA Instruments. The low-temperature range was obtained using a liquid nitrogen cooling system allowing reaching and stabilizing $93 \mathrm{~K}$ as a minimum temperature in the sample holder. The measurements were carried out using $5 \mathrm{mg}$ of powder sample sealed in aluminum capsules with a mechanical crimp and at a scan rate of $10 \mathrm{~K} / \mathrm{min}$. The calibration in temperature and energy was made with indium as standard sample, and the absolute heat capacity was determined measuring a sapphire sample as a reference material and following the zero heat flow procedure described by TA instruments. An accuracy of $\pm 0.25 \mathrm{~K}$ in temperature and $\pm 5 \%$ in the heat capacity was estimated in the whole temperature range.

We have performed diffuse reflectance measurements as a function of temperature and under various hydrostatic pressures using a home made device (transmitting medium is $\mathrm{He}$ gas) which was already described in Ref. 30 . The powder samples have been thermally cycled at least ten times be-

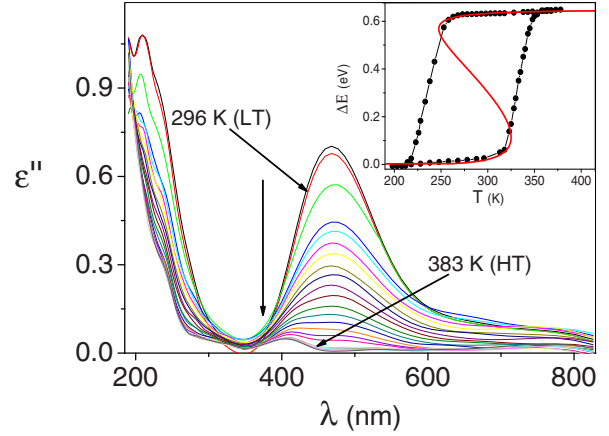

FIG. 1. (Color online) Thermal dependence of the imaginary part, $\epsilon^{\prime \prime}(\lambda)$, of the dielectric constant of $\mathrm{RbMn}\left[\mathrm{Fe}(\mathrm{CN})_{6}\right]$. The temperature increment between two successive curves is $4 \mathrm{~K}$. In inset, the temperature dependence of the energy shift in the edge of the MLCT band (estimated for $\varepsilon^{\prime \prime} \approx 0.3$ ). Symbols stands for the experimental data and the full line for the best fitting using Eq. (1). A Good agreement is obtained between these data and that of magnetic measurements reported in Ref. 25.

tween the liquid nitrogen and room temperature before starting the measurements. The repeated application of such thermal shocks led to automilling of the sample into smaller crystals, which is thought to release internal stresses due to grain boundaries and definitely improved the reproducibility of the hysteresis loop. The light source was a $100 \mathrm{~W}$ QTH (Quartz Tungsten Halogen) lamp with a $(900 \pm 50) \mathrm{nm}$ interferential filter located ahead of the optical fibers which carry light to the pressure cell. Typical intensity was $15 \mathrm{~mW} / \mathrm{cm}^{2}$.

\section{RESULTS AND DISCUSSION}

\section{A. Revisiting the thermal dependence of the ellipsometric spectra of $\mathrm{RbMn}\left[\mathrm{Fe}(\mathrm{CN})_{6}\right]$ (after Refs. 25 and 26)}

The ellipsometric investigation was performed in the wavelength range $240-800 \mathrm{~nm}$ and temperature range 260$380 \mathrm{~K}$ in heating and cooling modes. The imaginary part of the complex dielectric constant, $\varepsilon^{\prime \prime}(\lambda)$ shown in Fig. 1, in the heating case have been derived from the ellipsometric parameters, $\Delta(\lambda)$ and $\Psi(\lambda)$ in the frame of the semi-infinite model. ${ }^{31}$ The spectra follow a monotonic behavior with respect to temperature, and obey the Kramers-Kronig relations. ${ }^{25}$ Figure 1 evidences two main bands located in the UV and visible regions in both LT and HT states. At $296 \mathrm{~K}$ (LT state), the broad band observed at $468 \mathrm{~nm}$, contains two unresolved sub-bands which are assigned to $\mathrm{JT}^{3+} d-d$ $\left({ }^{5} \mathrm{~B}_{1 g} \rightarrow{ }^{5} \mathrm{~B}_{2 g},{ }^{5} \mathrm{E}_{g}\right)$ and IT charge transfer $\left(\mathrm{Fe}^{2+} \rightarrow \mathrm{Mn}^{3+}\right)$ transitions, while the narrow peak located at $210 \mathrm{~nm}$ corresponds to the metal-to-ligand charge transfer (MLCT) transition of $\left[\mathrm{Fe}^{2+}(\mathrm{CN})_{6}\right] \cdot{ }^{23}$ However, in the HT state, i.e., at 383 $\mathrm{K}$, a new band appears around $\lambda \simeq 405 \mathrm{~nm}$, which is assigned to the ligand-to-metal charge transfer transition of $\left[\mathrm{Fe}^{2+}(\mathrm{CN})_{6}\right]$, and a strong blue shift in the UV band is observed.

\section{On the origin of the energy shift in the MLCT band}

The results of Fig. 1, lead to an interesting observation concerning the shift of the bands with temperature. Indeed, it's clearly remarked that the broad (JT and IT) band at 468 
nm does not show a significant shift with temperature, while the edge of the MLCT band (centered at $210 \mathrm{~nm}$ in the LT phase), calculated as $\Delta E(T)=E\left(T=296 \mathrm{~K}, \varepsilon^{\prime \prime} \approx 0.3\right)$ $-E\left(T, \varepsilon^{\prime \prime} \approx 0.3\right)$, shows a remarkable blueshift when increasing temperature. Interestingly, the thermal behavior of this energy shift (shown in the inset of Fig. 1) follows a hysteresis loop, which well coincides to that of the magnetic data. ${ }^{25}$ This behavior, mainly due to the change in the metal-ligand distance upon the structural phase transition, indicates a variation in the electronic structure of the solid as the latticemisfit-induced strain relaxes upon the phase transition. Moreover we observed, small "splittings" in the UV band in the transition region, which we interpret as due to the anisotropic strain induced additional splittings in the MLCT band. The splittings are however hardly seen in the LT and HT phases, indicating a reduction in the strain-induced energy splitting, since the latter is maximum in the hysteresis region where the tetragonal and the cubic phases coexist, and where heterophase fluctuations are expected.

The effect of the strain on the electronic structure of the MLCT band can be analyzed in terms of the deformation potential theory, ${ }^{32}$ where a vibronic description ${ }^{33}$ of the solid (in the frame of the Born-Oppenheimer approximation) taking into account the cooperative JT effect has to be performed. The correlation between the energy shift in the MLCT band and the volume change which accompanies the first-order transition, is due to the interaction between the electronic (optical) and elastic (volume) degrees of freedom. This inter-relation will be studied here through the analysis of the thermal dependence of the refractive index in upcoming Sec. III B.

\section{Derivation of the theoretical hysteresis loop}

One of the most informative quantities in cooperative systems undergoing first-order transition is the interaction strength between the molecules, which monitors the width of the hysteresis loop. Here, we propose an analytical method allowing to evaluate quantitatively the value of the interaction parameter, denoted by $J$, in the frame of the phenomenological Ising model.

Indeed, the present first-order transition, driven by phonons, can be described by an Ising-like model, ${ }^{21,34}$ in which each molecule is associated with a two-state fictitious spin operator, $\sigma=-1,+1$, corresponding to the $\mathrm{Fe}^{\mathrm{II}}-\mathrm{Mn}^{\mathrm{III}}$ (LT) and $\mathrm{Fe}^{\mathrm{III}}-\mathrm{Mn}^{\mathrm{II}}$ (HT) configurations. The equation of state linking the HT fraction, $n_{\mathrm{HT}}$, and the temperature, is given in the mean-field approximation by ${ }^{25,34}$

$$
n_{\mathrm{HT}}=\frac{1}{2}+\tanh \beta\left[\frac{J}{2}\left(2 n_{\mathrm{HT}}-1\right)+\frac{k_{B} T}{2 R} \Delta S-\Delta\right],
$$

where $\Delta S$ is the molar entropy change, $\Delta$ is the energy gap between the two states at $0 \mathrm{~K}, \beta=1 / k_{B} T, k_{B}$ is the Boltzmann constant, and $R$ is the perfect gas constant. Here, for simplicity reasons, we consider the effective interaction parameter, $J$, as temperature independent, although in a rigorous treatment it is expected that $J$ must depend on temperature ${ }^{21,35}$ due to the role of the phonons in the mechanism of the present phase transition. Thus, the transition temperature is

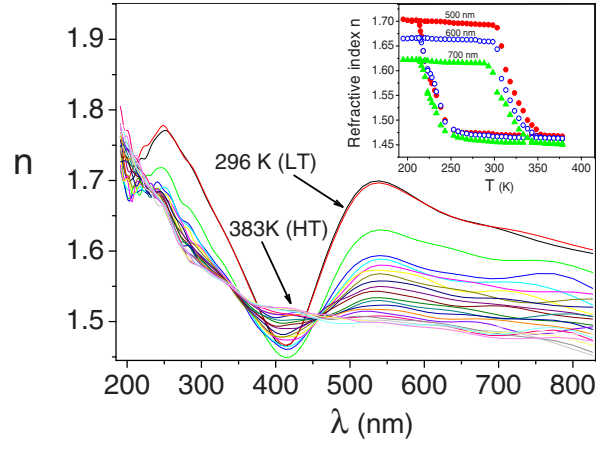

FIG. 2. (Color online) Thermal dependence of the refractive index spectra derived from ellipsometric measurements in the cooling mode. In the inset, are depicted the temperature dependence of the effective refractive index at various chosen wavelengths $\lambda=550,600$, and $700 \mathrm{~nm}$ (in the heating and cooling modes) showing thermal hysteresis, which will be connected to the change in the density of the material (see text for more explanation).

given here by $T_{1 / 2}=\left(2 R / k_{B}\right)(\Delta / \Delta S)$. The shift, $\Delta E(T)$ (in electron volt) of the MLCT band follows the simple relation, $\Delta E(T)=0.65 \times n_{\mathrm{HT}}(T)$, in which $n_{\mathrm{HT}}(T)$ is given by Eq. (1).

Expressing the temperature $T$ against $n_{\mathrm{HT}}$ in Eq. (1) and calculating the upper and lower "transition" temperatures limiting the width of the hysteresis, we could derive the following analytical expression of the interaction strength, $J$ $\simeq k_{B} T_{1 / 2}+\left(k_{B} \Delta T \times \Delta S / 4 R\right)$, where $T_{1 / 2} \simeq 280 \mathrm{~K}$, is the transition temperature, and $\Delta T(\simeq 100 \mathrm{~K})$ is the hysteresis width. The best fit between the theoretical curve (represented in full lines in the inset of in Fig. 1) and the experimental data is obtained for the interaction value $J=547( \pm 8) \mathrm{K}$ and the entropy change $\Delta S=60( \pm 7) \mathrm{J} \mathrm{K}^{-1} \mathrm{~mol}^{-1}$. The value of the entropy change will be discussed in details in the next sections.

\section{B. Access to elastic properties}

\section{Derivation of the volumetric thermal expansion coefficient from the refractive index spectra}

In this section, we show that one of the important consequences of the correlation between the structure and the electronic properties is the possibility to estimate the volumetric thermal expansion coefficient from the analysis of the refractive index, the thermal dependence of which is depicted in Fig. 2. The coefficient of the volumetric thermal expansion, $\alpha_{T}=[(\partial V / \partial T)] / V$, the knowledge of which constitutes an important step in the determination of the elastic properties of the material, can be derived from the empirical linear equation of Gladstone-Dale, ${ }^{36,37} n=1+r \rho$, linking the change in the refractive index, $n(T)$, with the density of the material. There, $r$ is a constant, $n$ and $\rho$ are the refractive index and the density of the material, respectively. It should be remarked here, that the refractive index, $n$, has to be calculated in the transparency region of the material, in other words, far from the absorption bands. Moreover, this method cannot be applied at the isobestic point, like one observed at $\lambda \approx 460 \mathrm{~nm}$ in the refractive index spectra of Fig. 2 .

We have recorded the temperature dependence of the refractive index spectra (Fig. 2) from which we derived the temperature dependence of the refractive index at three wavelengths, $\lambda=550 \mathrm{~nm}, \lambda=600 \mathrm{~nm}$, and $\lambda=700 \mathrm{~nm}$, in order to check the consistency of our approach. We have 
TABLE I. Volumetric thermal expansion coefficient, $\alpha_{T}$, in the LT and HT phases derived from the refractive index spectra of Fig. 2 using Galdstone's law at different wavelengths. The results show a weak dependence of $\alpha_{T}^{\mathrm{LT}}$ and $\alpha_{T}^{\mathrm{HT}}$ on the wavelength values up to fluctuations.

\begin{tabular}{lcccc}
\hline \hline$\lambda(\mathrm{nm})$ & 550 & 600 & 700 \\
$\alpha_{T}^{\mathrm{LT}}\left(\times 10^{-4}\right.$ & $\left.\mathrm{K}^{-1}\right)$ & $1,4( \pm 0.2)$ & $1,2( \pm 0.2)$ & $1,3( \pm 0.1)$ \\
$\alpha_{T}^{\mathrm{HT}}\left(\times 10^{-4}\right.$ & $\left.\mathrm{K}^{-1}\right)$ & $1,6( \pm 0.3)$ & $1,5( \pm 0.3)$ & $1,7( \pm 0.3)$ \\
\hline
\end{tabular}

found that, once the temperature is fixed, the thermal expansion coefficient, $\alpha_{T}$, is almost the same for the different wavelengths up to fluctuations (as seen in Table I). Thus, we could derive the thermal dependence of $n$, depicted in inset of Fig. 2, which shows a hysteresis loop correlated with that of magnetic data of Fig. 1. Straightforwardly, the volumetric thermal expansion is then derived as $\alpha_{T}=-(d n / d T /(n-1))$, which exhibits two maxima corresponding to the upper and lower transition temperatures of the hysteresis loop. However, from the physical point of view, the thermal expansion coefficient has a meaning only in the LT and HT phase, far from any phase transition region. We obtained in the LT and HT phases the average respective values $\alpha_{T}^{\mathrm{LT}}$ $\simeq 1.3( \pm 0.2) 10^{-4} \mathrm{~K}^{-1}$ and $\alpha_{T}^{\mathrm{HT}}=1.6( \pm 0.3) 10^{-4} \mathrm{~K}^{-1}$. Such values are in very good agreement with the zero thermal expansion character, reported in literature, ${ }^{38}$ for this family of bistable solids. Neglecting the anharmonic effects (due to the zero thermal expansion character of the sample), the temperature dependence of the unit cell volume can be well approximated using the relation $V(T) \simeq n_{\mathrm{HT}} \times \delta V+V_{\mathrm{LT}}$, in which $\Delta V=V_{\mathrm{HT}}-V_{\mathrm{LT}} \approx 112 \AA^{3}$ and $V_{\mathrm{LT}}=1057 \AA^{3}\left(V_{\mathrm{HT}}\right)$ is the volume of the unit cell in the LT (HT) phase.

\section{Bulk modulus}

Next, we are interested in one of the most informative quantities for the elastic properties, which is the bulk modulus, which connects with various other physical properties, such as sound velocity and Debye temperature. Our strategy here consist on deriving the compressibility $\chi=|\partial V / \partial P / V|$ $=\alpha_{T}(d T / d p)$, where $\alpha_{T}$ is the volumetric thermal expansion and $d T / d p$ is a quantity which can be interpreted as the pressure dependence of the transition temperature. Although in the general case, $(\partial T / \partial p)$ is temperature dependent, in the present case we calculate it using the Clapeyron's equation. Indeed, at the transition temperature, we have $(d T / d p)_{T_{1 / 2}}$ $=(\Delta V / \Delta S)$, where $\Delta S$ and $\Delta V$ are the entropy and the volume change at the transition, respectively. Thus, the determination of the bulk modulus imposes to evaluate $(d T / d p)_{T_{1 / 2}}$ which will be estimated from diffuse reflectivity measurements under pressure, as follows.

We recorded thermal hysteresis loops at increasing pressure values (from 150 to 850 bars). Temperature was scanned every $0.5-1 \mathrm{~K}$, in the heating and cooling modes, successively. We checked that the initial hysteresis loop at 1 bar was obtained again after releasing the maximum pressure, and also controlled that the pressure effect was reproducible. The results, shown in Fig. 3, demonstrate a sizable effect of pressure on the transition temperature, while it is less visible on the width of the hysteresis, as depicted in the inset where the pressure dependence of the upper and lower transition

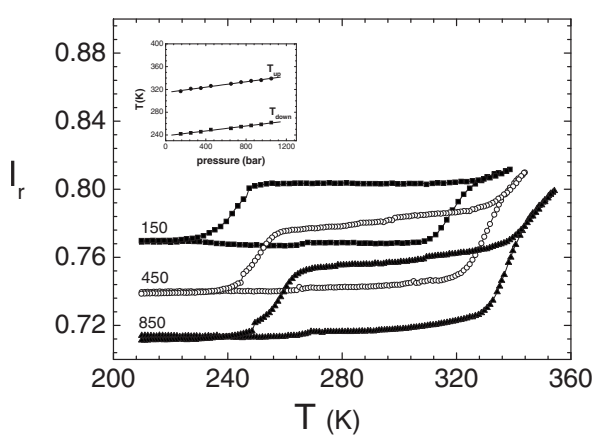

FIG. 3. Thermal evolution of the reflectivity signal recorded at various pressures 150,450 , and 850 bar. In the inset is represented the phase diagram $T-p$ where $T_{u p}$ and $T_{d o w n}$ are upper and lower transition temperatures of the hysteresis loop.

temperatures of the hysteresis loop are represented. A linear behavior of the transition temperatures is obtained, in good agreement with Clapeyron's equation previously discussed. The measured average value of the slope $(d T / d p)_{T_{1 / 2}}$ is found to be $(d T / d p)_{T_{1 / 2}} \approx 26 \mathrm{~K} / \mathrm{kbar}$; comparable to the values $20-25 \mathrm{~K} / \mathrm{kbar}$ of SC materials reported in literature. ${ }^{39,40}$

The bulk modulus, $B(T)$, of the material is related to the previous quantities by $B(T)=\left(1 / \alpha_{T}(d T / d p)\right)$, which leads to the following typical values $B_{\mathrm{LT}}=0.30( \pm 0.02) 10^{11} \mathrm{~Pa}$ and $B_{\mathrm{HT}}=0.23( \pm 0.02) 10^{11} \mathrm{~Pa}$ in the LT and HT states, respectively. These values are one order of magnitude lower than the value $2.06 \times 10^{11} \mathrm{~Pa}$ of the bulk modulus of steel, for example, reported in literature. ${ }^{41}$

\section{Sound velocity and Debye temperature}

Using the bulk modulus values and the thermal dependence of the density of the sample, it is straightforward to derive the effective sound velocity, $v=\sqrt{B / \rho}$ with temperature, which writes as

$$
v(T)=\sqrt{\frac{1+n_{\mathrm{HT}}\left(\frac{V_{\mathrm{HT}}}{V_{\mathrm{LT}}}-1\right)}{\alpha \times \frac{\partial T}{\partial p} \rho_{\mathrm{LT}}}} .
$$

There, $\rho_{\mathrm{LT}}\left(=2.2 \mathrm{~g} / \mathrm{cm}^{3}\right)$ is the density of the sample in the LT phase. We estimated the value of the effective sound velocity as $v_{\mathrm{LT}} \simeq 4300( \pm 300) \mathrm{m} / \mathrm{s} \quad\left[v_{\mathrm{HT}} \simeq 3600( \pm 300) \mathrm{m} / \mathrm{s}\right]$ in the LT (HT) state, which are smaller (but of the same order of magnitude) than that of the sound velocity in steel, $v=5100 \mathrm{~m} / \mathrm{s} .{ }^{41}$ In addition, it is remarked that $v_{\mathrm{LT}}>v_{\mathrm{HT}}$, which is consistent with the fact that the LT phase is more rigid than the HT phase.

Another physical quantity of importance in solid state physics is the Debye temperature, which writes for a three dimensional lattice as $\theta_{D}=v\left(\hbar / k_{\mathrm{B}}\right)\left(6 \pi^{2} N / V\right)^{1 / 3}$, where $N$ is the number of (Fe-Mn) oscillators in the unit cell and $V$ its volume. Typical values of $\theta_{D}$ deduced from SE data in the LT and HT states are $\theta_{D}^{\mathrm{LT}} \simeq 360( \pm 25) \mathrm{K}$ and $\theta_{D}^{\mathrm{HT}}$ $\simeq 290( \pm 20) \mathrm{K}$, respectively.

To check the accuracy of the present values of Debye temperature values found by the combination of SE and reflectivity data, we performed Mössbauer spectrometry stud- 

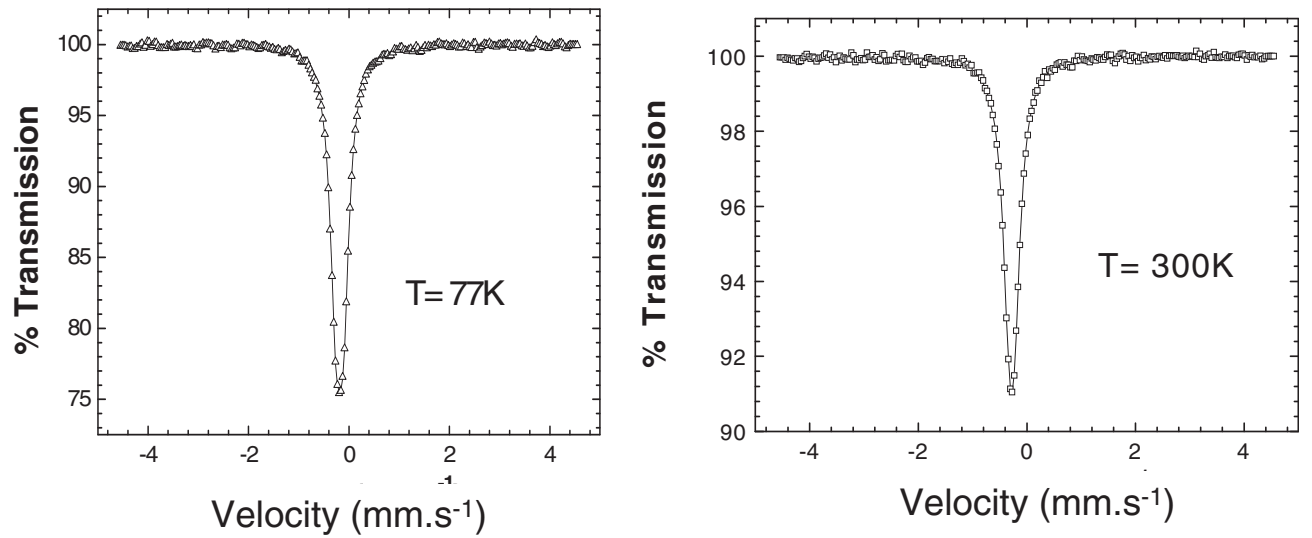

FIG. 4. Mössbauer spectra at 77 and $300 \mathrm{~K}$ of $\mathrm{RbMn}\left[\mathrm{Fe}(\mathrm{CN})_{6}\right]$ showing a very weak dependence of the shape of the spectra in the LT and HT phases. See text for details.

ies, for which we show in Fig. 4 the spectra at $77 \mathrm{~K}$ and 300 $\mathrm{K}$, in the $\mathrm{Fe}^{\mathrm{II}}$ and $\mathrm{Fe}^{\mathrm{III}}$ states, respectively. In a first examination, it seems that Mössbauer spectra do not detect clearly the thermally-induced transition $\mathrm{Fe}^{\mathrm{II}} \mathrm{LS}$ to $\mathrm{Fe}^{\mathrm{III}}$. In particular, we do not detect any change in the quadrupole splitting, which remains negligible in both states. Indeed, while the environment of $\mathrm{Mn}$ is strongly changed at the transition, that of Fe remains quite invariant, with only a small variation at the charge transfer transition. However, a fine analysis of the thermal behavior of the isomer shift (see Table II), which is known to be sensitive to the electronic state of $\mathrm{Fe}$ and to the phonon density in the lattice, clearly exhibits the existence of a thermal hysteresis loop around the transition temperature, as shown in Fig. 5.

Another quantity of importance in Mössbauer spectrometry is the recoil-free-fraction (connected to the DebyeWaller factor) since its temperature dependence is for evaluating the Debye temperature in the HT and LT phases. Thus, we have a new tool to determine the values of the Debye temperature and to compare them to those obtained by the combination of SE and reflectivity measurements under pressure.

The temperature dependence of the Debye-Waller factor is shown in Fig. 6. The HT and LT phases are clearly distinguished by two straight lines having different slopes. In the HT limit, the Debye temperature $\theta_{D}$ is related to the slope of the absorption factor, $f(T)$, by $(d \ln f / d T) \simeq-136 / \theta_{D}^{2}{ }^{42}$ It yields to $\theta_{D}^{\mathrm{LT}} \simeq 332( \pm 7) \mathrm{K}$ and $\theta_{D}^{\mathrm{HT}} \simeq 280( \pm 11) \mathrm{K}$. These values are in good agreement with those obtained by SE. The clear tendency $\theta_{D}^{\mathrm{LT}}>\theta_{D}^{\mathrm{HT}}$, also well agrees with the x-ray diffraction data ${ }^{20}$ which evidence a strong lattice contraction upon the HT to LT transformation. In addition, recent Mössbauer spectrometry studies ${ }^{43,44}$ on the same system but with a different stoichiometry gave $\theta_{D}^{\mathrm{LT}} \simeq 333( \pm 14) \mathrm{K}$ and $\theta_{D}^{\mathrm{HT}}$ $\simeq 280( \pm 24) \mathrm{K}$, in quite good agreement with the present results. It is also important to notice that typical values of Debye temperature in SC solids ${ }^{42}$ are $\theta_{D}^{\mathrm{LT}} \simeq 170 \mathrm{~K}$ and $\theta_{D}^{\mathrm{HT}}$ $\simeq 140 \mathrm{~K}$, which are almost two times smaller than that of the present PBAs. This result can be explained by the strong covalent character of PBAs, while the SC materials are molecular crystals.

\section{On the entropy change at the transition}

It is worth to notice that we could determine in the present work the entropy change at the transition by using two different and independent methods: (i) from the theoretical fitting of the ellipsometric experimental hysteresis loop of the energy shift (shown in the inset of Fig. 1) leading to $\Delta S=60$ ( \pm 6$) \mathrm{J} \mathrm{K}^{-1} \mathrm{~mol}^{-1}$ and (ii) from reflectivity under pressure data by the Clapeyron's equation $(d T / d p)$ $=\Delta V / \Delta S=26 \mathrm{~K} / \mathrm{kbar}$ (where the volume change in the unit cell $\left(\Delta V=V_{\mathrm{HT}}-V_{\mathrm{LT}} \approx 28 \AA^{3}\right) \quad$ leading to $\Delta S$ $=64( \pm 6) \mathrm{J} \mathrm{K}^{-1} \mathrm{~mol}^{-1}$. Thus, these two methods lead to close values of entropy change at the transition, which disagree with the value $\Delta S \approx 6 \mathrm{~J} \mathrm{~K}^{-1} \mathrm{~mol}^{-1}$, previously reported in the literature, ${ }^{19,45}$ and which has been attributed to the electronic entropy gain. Indeed, the LT and HT phases of $\mathrm{RbMnFe}(\mathrm{CN})_{6}$ consist in $\left[\mathrm{Mn}^{\mathrm{III}}\left({ }^{5} \mathrm{~B}_{1 g}\right)-\mathrm{Fe}^{\mathrm{II}}\left({ }^{1} \mathrm{~A}_{1 g}\right)\right]$ and $\left[\mathrm{Mn}^{\mathrm{II}}\left({ }^{6} \mathrm{~A}_{1 g}\right)-\mathrm{Fe}^{\mathrm{III}}\left({ }^{2} \mathrm{~T}_{2 g}\right)\right]$, respectively, and the multiplicity arising from the spin-manifold degeneracy (the orbital degeneracy is not discarded here, because the saturated value of $\chi_{m} T$ at HT supports the absence of orbital contribution) is $\Delta S=R \ln (12 / 5)=7.3 \mathrm{~J} \mathrm{~K}^{-1} \mathrm{~mol}^{-1}$.

However, this small value of entropy change cannot explain with reasonable thermodynamic values the large width of the thermal hysteresis loop. Moreover, recent studies ${ }^{46}$ on a similar PBA, $\mathrm{NaCo}\left[\mathrm{Fe}(\mathrm{CN})_{6}\right]_{0.74} \cdot 3.4 \mathrm{H}_{2} \mathrm{O}$, has given an entropy change at the transition, $\Delta S \simeq 60 \mathrm{~J} \mathrm{~K}^{-1} \mathrm{~mol}^{-1}$, in quite good agreement with that of the present data.

TABLE II. The least-square fit parameters derived from the analysis of the Mössbauer spectra of $\mathrm{RbMn}\left[\mathrm{Fe}(\mathrm{CN})_{6}\right]$ for selected temperatures.

\begin{tabular}{|c|c|c|c|c|c|c|c|c|c|}
\hline $\mathrm{T}(\mathrm{K})$ & 77.8(LT) & 200 & 220 & 230 & 240 & 250 & 280 & 290 & 300 \\
\hline $\mathrm{Di}(\mathrm{mm} / \mathrm{s})$ & $0.186(3)$ & $0.219(2)$ & $0.228(5)$ & $0.232(5)$ & $0.237(2)$ & $0.242(6)$ & $0.256(5)$ & $0.283(4)$ & $0.299(1)$ \\
\hline$\Gamma(\mathrm{mm} / \mathrm{s})$ & $0.142(3)$ & $0.149(5)$ & $0.152(1)$ & $0.148(1)$ & $0.150(5)$ & $0.150(1)$ & $0.146(1)$ & $0.182(1)$ & $0.183(5)$ \\
\hline$\chi^{2}$ & 0.446 & 0.516 & 0.503 & 0.546 & 0.506 & 0.479 & 0.487 & 0.547 & 0.419 \\
\hline
\end{tabular}




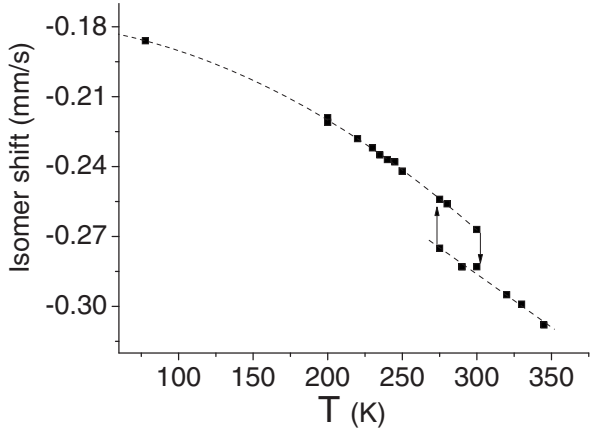

FIG. 5. Thermal dependence of the isomer shift. The hysteresis loop between 250 and $300 \mathrm{~K}$ is in agreement with that of SE and calorimetric data of respective Figs. 1 and 7 .

To solve the apparent discrepancy between the present and the previous data of literature, we have performed calorimetric measurements (DSC measurements) on the title compound. In Fig. 7, the heat capacity of the sample is shown in the $200-350 \mathrm{~K}$ temperature range. There is a peak at $T_{\max }$ (heating) $=299 \mathrm{~K}$ corresponding to the LT-HT transition. In addition, heat capacity data (digitalized) obtained by relaxation calorimetry from Ref. 19 are included for comparison. There is a good agreement (taking into account the accuracy of both techniques and that the samples were not the same) with respect to the lattice (nonanomalous) contribution. However, there is a large discrepancy for the LT to HT transition, since we derive from our measurements an enthalpy and entropy changes of $17 \pm 1 \mathrm{~kJ} / \mathrm{mol}$ and $61 \pm 5 \mathrm{~J} \mathrm{~mol}^{-1} \mathrm{~K}^{-1}$, respectively. It is worth to mention that the present entropy change is in good agreement with that deduced from reflectivity and ellipsometry investigations. Moreover, these values are also in good agreement with other recently reported data $^{47}$ on a similar PBA. We think that the main reason of difference between the present data and the previous studies, comes from the fact that the relaxation calorimetry (used in previous studies) have some difficulties to catch the true enthalpy change when a first-order transition is measured. ${ }^{48}$

\section{CONCLUSION}

In summary, variations in the dielectric functions of $\mathrm{RbMn}\left[\mathrm{Fe}(\mathrm{CN})_{6}\right]$ have been investigated by SE measurements at different temperatures. As the temperature is raised,

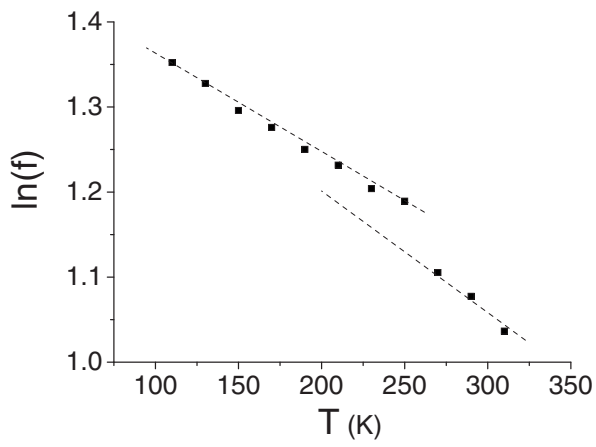

FIG. 6. Experimental data of the absorption factor, $f$, characterized by a jump from the LT and HT states. The dashed lines are the best linear fit.

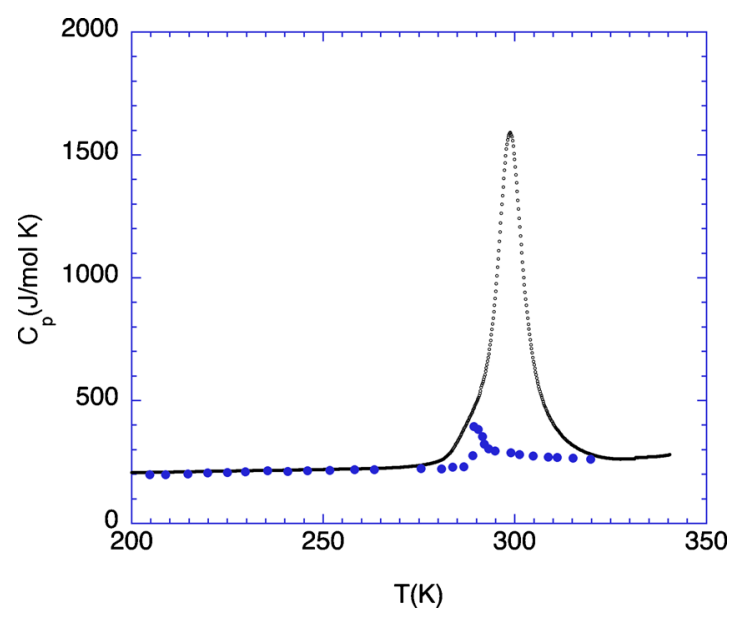

FIG. 7. (Color online) Heat capacity of $\mathrm{Rb}_{0.94} \mathrm{Mn}\left[\mathrm{Fe}(\mathrm{CN})_{6}\right]_{0.98} \cdot 0.2 \mathrm{H}_{2} \mathrm{O}$ in the 200 to $350 \mathrm{~K}$ temperature range. Closed circles (blue points) are previously reported data of literature (Ref. 19), leading to $\Delta S \simeq 6 \mathrm{~J} \mathrm{~K}^{-1} \mathrm{~mol}^{-1}$ and small points are the present data derived from DSC measurements, leading to an entropy change $\Delta S=61 \pm 5 \mathrm{~J} \mathrm{~mol}^{-1} \mathrm{~K}^{-1}$. The scan rate was 10 $\mathrm{K} / \mathrm{min}$.

the MLCT band, localized in the UV region, shifts to higher energies due to the change in the metal-ligand bond lengths which accompanies the phase transition. The analysis of the MLCT band shift using the extinction coefficient data yields a thermal hysteresis, which has been fitted using a simple two-states model commonly used to describe magnetic properties of cooperative SC solids. Furthermore, we have used for the first-time the thermal dependence of the refractive index, from which we derived the thermal expansion coefficient through the empirical Gladstone-Dale equation which links the change in the refractive index with the density of the material. The entropy change at the transition, has been inferred from the width of the hysteresis loop and found in very good agreement with the calorimetric measurements reported in the present work. In addition, the bulk modulus and sound velocity values obtained from the combination of SE and reflectivity under pressure measurements are also in agreement with textbook values. Finally, and in order to check the consistency of SE predictions concerning the rigidity of the solid, we performed independent Mössbauer spectrometry experiments which yield very close Debye temperatures values (in the LT and HT phases) with those derived from SE investigations. Next step will be devoted to use SE to investigate nonequilibrium properties of switchable solids, such as relaxation of photo-induced or thermally quenched states.

\section{SUPPORTING INFORMATION: ON THE RELATION BETWEEN THE SHIFT OF THE MLCT BAND AND THE VOLUME CHANGE AT THE TRANSITION}

We describe here the potential energy of the $\mathrm{RbMnFe}(\mathrm{CN})_{6}$ solid as a set of two vibronic oscillators along the effective metal-ligand (Mn-NC-Fe) coordinate. The potential energies in the LT and HT states are given by $\left\langle\psi_{A} \mid H \psi_{A}\right\rangle=-\Delta+1 / 2 k x^{2}$ and $\left\langle\psi_{B} \mid H \psi_{B}\right\rangle=\Delta+1 / 2 k^{\prime}\left(x-x_{0}\right)^{2}$, where subscripts $A$ and $B$ correspond to the LT and HT states. $\Delta$ is the ligand-field energy, $x$ is the effective metal- 


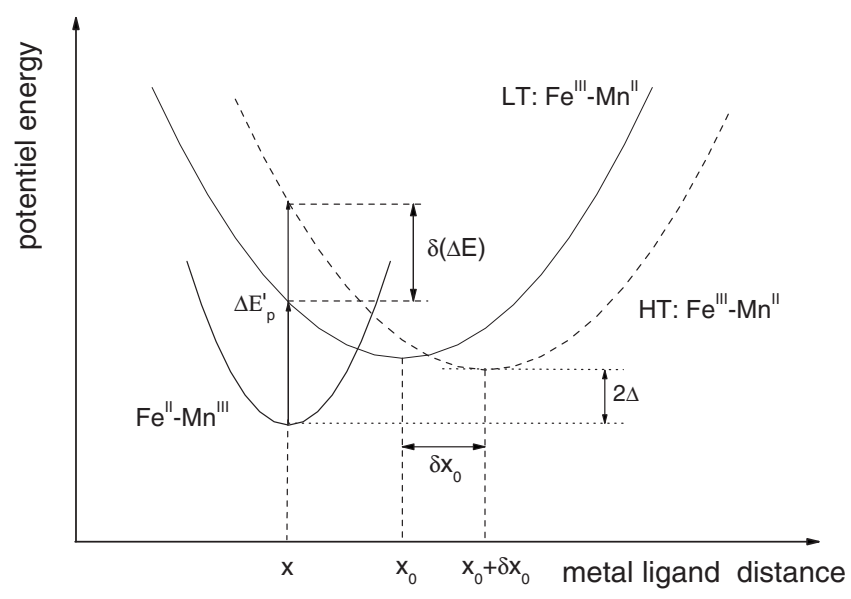

FIG. 8. Potential energy of the molecule as function of the metal-ligand distance in the LT and HT states. The bold vertical arrow is the FranckCondon transition in both states.

ligand distance, and $x_{0}$ is the molecular distortion resulting from the charge transfer between $\mathrm{Fe}$ and $\mathrm{Mn}$ ions. In the Born-Oppenheimer approach, and in the harmonic limit, we can consider in a first approximation that the electronic overlapping between the two wave functions $\left|\psi_{A}\right\rangle$ and $\left|\psi_{B}\right\rangle$ is smaller than the phonon energy. Therefore the FranckCondon transitions between the electronic states $\left|\psi_{A}\right\rangle$ and $\left|\psi_{B}\right\rangle$, occurring at fixed nuclear coordinate, $x=0$, have the transition energy $\Delta E_{0}=2 \Delta+1 / 2 k x_{0}^{2}$ in the LT state (see Fig. $8)$. At high-temperature, there is an expansion $\delta x_{0}$ of the metal-ligand distance, leading to a change in the relative equilibrium positions of the two associated harmonic oscillators. For FeRbMn the relative change is $\delta x_{0} / x_{0} \simeq 3 \%$. Assuming the other parameters of the model as unchanged (which is not exactly true due to the change in symmetry), the new transition energy is given by $\Delta E_{0}^{\prime}=2 \Delta+1 / 2 k(x$ $\left.-x_{0}\right)^{2}\left[1+\frac{\delta x_{0}}{\left(x-x_{0}\right)}\right]$, which leads to the relative variation in transition energy of $\delta(\Delta E) / \Delta E \simeq 2 \delta x_{0} / x_{0}$ in the case where the ligand field energy is smaller than the elastic energy $(2 \Delta$ $\ll 1 / 2 k x_{0}^{2}$ ), an hypothesis which is clearly valid here (see Fig. $8)$.

In the cubic symmetry, and for an isotropic volume expansion, the relative volume expansion, $\Delta V / V$, can be easily related to the relative metal-ligand distance change as, $\Delta V / V \simeq 3 \delta x_{0} / x_{0}$, where $V$ is the volume of the unit cell. Finally, it is straightforward to establish a direct relation between the relative energy shift in the optical transition and the volume change as $[(\delta(\Delta E)) /(\Delta E)] /[(\Delta V) / V] \simeq 0.7$.

Concomitantly, we derive from the inset of Fig. 1 that $\delta(\Delta E) / \Delta E \approx 12 \%-14 \%$ in the transition region. In addition, a measured relative volume change in $\Delta V / V \approx 10 \%$ is reported in literature, ${ }^{11,19}$ leading to the ratio $[(\delta(\Delta E)) /(\Delta E)] /[(\Delta V) / V] \approx 1.2$. This value is a bit far form the theoretical value, $\sim 0.7$, derived from our oversimplified model. Two reasons may explain the previous tendency: (i) in our model, we assumed for simplicity that the energies of the excited state $\mathrm{Fe}^{\mathrm{III}}-\mathrm{Mn}^{\mathrm{II}}$ in the $\mathrm{LT}$ phase and that of $\mathrm{Fe}^{\mathrm{III}}-\mathrm{Mn}^{\mathrm{II}}$ in the HT phase are equal (see the minima of the corresponding parabola depicted in Fig. 8). In a more realistic description, an energy gap between the $\mathrm{HT}-\mathrm{Fe}^{\mathrm{III}}-\mathrm{Mn}^{\mathrm{II}}$ and the $\mathrm{LT}-\mathrm{Fe}^{\mathrm{III}}-\mathrm{Mn}^{\mathrm{II}}$ must be included, leading to enhance the theoretical value of the ratio $(\delta(\Delta E) / \Delta E)$. (ii) Another assumption, implicitly introduced in the model, lies with the equal frequencies of the LT and HT of Fe ${ }^{\mathrm{III}}-\mathrm{CN}-\mathrm{Mn}^{\mathrm{II}}$ oscillators. In a similar compound, Raman spectroscopy investigations ${ }^{47}$ revealed the existence of two $\mathrm{CN}$ stretching modes around 2161 and $2170 \mathrm{~cm}^{-1}$ in the HT state, while the LT phase $\mathrm{Fe}^{\mathrm{II}}-\mathrm{CN}-\mathrm{Mn}^{\mathrm{III}}$ is characterized by two lower frequency modes around 2094 and $2114 \mathrm{~cm}^{-1}$. This behavior is surprising and suggest that the rigidity of the lattice increases with temperature, which is in contradiction with Mössbauer spectrometry and ellipsometry data leading to a stronger Debye temperature in the LT phase. However, this apparent contradiction can be left when considering the symmetry change which accompanies the charge transfer transition. Based on the previous Raman data, the $\mathrm{HT}-\mathrm{Fe}^{\mathrm{III}}-\mathrm{Mn}^{\mathrm{II}}$ state has stiffer vibration spectrum at the molecular scale than that of $\mathrm{LT}-\mathrm{Fe}^{\mathrm{III}}-\mathrm{Mn}^{\mathrm{II}}$ phase, which increases (at least by a factor $\left.\left(\omega_{\mathrm{HT}} / \omega_{\mathrm{LT}}\right)^{2} \approx 1.07\right)$ the stiffness of the elastic constant of the excited double well potential of Fig. 8. It results an increase in the theoretical optical gap $\delta(\Delta E)$ which will also contribute to increase the theoretical ratio $\delta(\Delta E) / \Delta E$ in order to approach the experimental value 1.2. The extension of this simple theoretical approach including the effect of the interactions will be developed elsewhere.

\section{ACKNOWLEDGMENTS}

This work was supported by the "Ministère de l'Enseignement Supérieur et de la Recherche" PPF contract, UTIQUE program N18455RJ, AUF program, the Spanish MICINN and FEDER under Project No. MAT2007-61621, Consolider-Ingenio under Grant No. CSD 2007-00010, and European Union Network of Excellence MAGMANet (Contract No. NMP3-CT-2005-515767-2), CNRS, Université de Versailles Saint-Quentin-en-Yvelines. All of them are gratefully acknowledged.

${ }^{1}$ E. Konig, Struct. Bonding (Berlin) 76, 51 (1991); P. Gütlich, A. Hauser, and H. Spiering, Angew. Chem. 106, 2109 (1994).

${ }^{2}$ O. Sato, S. Hayami, Y. Einaga, and Z. Z. Gu, Bull. Chem. Soc. Jpn. 76, 443 (2003)

${ }^{3}$ S. Ferlay, T. Mallah, R. Ouahès, P. Veillet, and M. Verdaguer, Nature (London) 378, 701 (1995).

${ }^{4}$ O. Kahn, J. Krober, and C. Jay, Adv. Mater. 11, 4 (1992).

${ }^{5}$ Y. Garcia, V. Ksenofontov, and P. D. Gütlich, Hyperfine Interact. 543, 139 (2002).

${ }^{6}$ O. Kahn and E. Codjovi, Philos. Trans. R. Soc. London, Ser. A 354, 359 (1996).

${ }^{7}$ E. Freysz, S. Montant, S. Létard, and J. F. Létard, J. Chem. Phys. 394, 318 (2004).

${ }^{8}$ S. Ohkoshi, H. Tokoro, M. Utsunomiya, M. Mizuno, M. Abe, and K. Hashimoto, J. Phys. Chem. B 106, 2423 (2002).

${ }^{9}$ H. Tokoro, T. Matsuda, K. Hashimoto, and S. Ohkoshi, J. Appl. Phys. 97, 10M508 (2005).

${ }^{10}$ H. Tokoro, S. Ohkoshi, and K. Hashimoto, Appl. Phys. Lett. 82, 1245 (2003).

${ }^{11}$ Y. Moritomo, A. Kuriki, K. Ohoyama, H. Tokoro, S. Ohkoshi, K. Hashimoto, and N. Hamada, J. Phys. Soc. Jpn. 72, 456 (2003).

${ }^{12}$ K. Kato, Y. Moritomo, M. Takata, M. Sakata, M. Umekawa, N. Hamada, S. Ohkoshi, H. Tokoro, and K. Hashimoto, Phys. Rev. Lett. 91, 255502 (2003).

${ }^{13}$ S. Margadonna, K. Prassides, and A. N. Fitch, Angew. Chem., Int. Ed. 43, 6316 (2004).

${ }^{14}$ T. Nuida, T. Matsuda, H. Tokoro, S. Sakurai, K. Hashimoto, and S. Oh- 
kosh, J. Am. Chem. Soc. 127, 11604 (2005).

${ }^{15}$ L. Egan, T. Matsuda, H. Tokoro, S. Sakurai, K. Hashimoto, and S. Ohkosh, J. Am. Chem. Soc. 128, 6034 (2006).

${ }^{16}$ S. Ohkoshi, H. Tokoro, T. Matsuda, H. Takahashi, H. Irie, and K. Hashimoto, Angew. Chem., Int. Ed. 46, 3238 (2007)

${ }^{17}$ P. N. Schatz, T. Matsuda, H. Tokoro, S. Sakurai, K. Hashimoto, and S. Ohkosh, J. Chem. Phys. 45, 722 (1966).

${ }^{18}$ T. Mahfoud, G. Molnár, S. Bonhommeau, S. Cobo, L. Salmon, P. Demont, H. Tokoro, S. Ohkoshi, K. Boukheddaden, and A. Bousseksou, J. Am. Chem. Soc. 131, 15049 (2009).

${ }^{19}$ H. Tokoro, S. Ohkoshi, T. Matsuda, and K. Hashimoto, Inorg. Chem. 43, 5231 (2004).

${ }^{20}$ S. Ohkoshi, H. Tokoro, and K. Hashimoto, Coord. Chem. Rev. 249, 1830 (2005).

${ }^{21}$ H. Tokoro, S. Miyashita, K. Hashimoto, and S. Ohkoshi, Phys. Rev. B 73 172415 (2006)

${ }^{22}$ Y. Moritomo, K. Kato, A. Kuriki, M. Takata, M. Sakata, H. Tokoro, S Ohkoshi, and K. Hashimoto, J. Phys. Soc. Jpn. 71, 2078 (2002).

${ }^{23}$ S. Ohkoshi, T. Nuida, T. Matsuda, H. Tokoro, and K. Hashimoto, J. Mater Chem. 15, 3291 (2005).

${ }^{24}$ E. D. Loutete-Dangui, F. Varret, E. Codjovi, P. R. Dahoo, H. Tokoro, S Ohkoshi, C. Eypert, J. F. Létard, J. M. Coanga, and K. Boukheddaden, Phys. Rev. B 75, 184425 (2007).

${ }^{25}$ E. D. Loutete-Dangui, E. Codjovi, H. Tokoro, P. R. Dahoo, S. Ohkoshi, and K. Boukheddaden, Phys. Rev. B 78, 014303 (2008).

${ }^{26} \mathrm{~K}$. Boukheddaden, E. D. Loutete-Dangui, M. Koubaa, and C. Eypert, Phys. Status Solidi C 5, 1003 (2008).

${ }^{27}$ H. Tokoro, T. Matsuda, T. Nuida, Y. Moritomo, K. Ohoyama, E. D. Loutete Dangui, K. Boukheddaden, and S. Ohkoshi, Chem. Mater. 20, 423 (2008).

${ }^{28}$ J. Humlíček, E. Schmidt, L. Bočánek, R. Švehla, and K. Ploog, Phys. Rev. B 48, 5241 (1993)

${ }^{29}$ R. M. A. Azzam and N. M. Bashara, Ellipsometry and Polarized Light (North-Holland, Amsterdam, 1977).

${ }^{30}$ W. Morscheidt, J. Jeftic, E. Codjovi, J. Linares, A. Bousseksou, H. Constant-Machado, and F. Varret, Meas. Sci. Technol. 9, 1311 (1998); J. Jeftic, N. Menendez, A. Wack, E. Codjovi, J. Linares, A. Goujon, G. Hamel, S. Klotz, G. Syfosse, and F. Varret, ibid. 10, 1059 (1999); See also J. Jeftic, U. Kindler, H. Spiering, and A. Hauser, ibid. 8, 479 (1997); R. Tanasa, A. Stancu, J. F. L'etard, E. Codjovi, J. Linares, and F. Varret,
Chem. Phys. Lett. 443, 435 (2007).

${ }^{31}$ H. G. Tompkins and W. A. McGahan, Spectroscopic Ellipsometry and Reflectometry (Wiley, New York, 1999).

${ }^{32}$ F. H. Pollak, in Strained-Layers Superlattices: Physics, Semiconductors and Semimetals, edited by T. P. Pearsall (Academic, London, 1992), Vol. 32, Chap. 2.

${ }^{33}$ K. Boukheddaden, M. Nishino, and S. Miyashita, Phys. Rev. Lett. 100, 177206 (2008).

${ }^{34}$ K. Boukheddaden, I. Shteto, B. Hôo, and F. Varret, Phys. Rev. B 62, 14806 (2000)

${ }^{35}$ K. Boukheddaden, S. Miyashita, and M. Nishino, Phys. Rev. B 75, 094112 (2007).

${ }^{36}$ D. Dale and F. Gladstone, Philos. Trans. R. Soc. London 153, 317 (1864).

${ }^{37}$ L.-X. Liu, Q. Liu, C.-G. Shao, Y.-T. Zhang, J. Luo, and V. Milyukov, Chin. Phys. Lett. 25, 4203 (2008); see also L.-X. Liu, C.-G. Shao, L.-C. Tu, and J. Luo, ibid. 26, 010403 (2009).

${ }^{38}$ T. Matsuda, H. Tokoro, K. Hashimoto, and S. Ohkoshi, Dalton Trans. 42, 5046 (2006).

${ }^{39}$ A. Sava, C. Enachescu, A. Stancu, K. Boukheddaden, E. Codjovi, I. Maurin, and F. Varret, J. Optoelectron. Adv. Mater. 5, 977 (2003).

${ }^{40}$ A. Rotaru, F. Varret, E. Codjovi, K. Boukheddaden, J. Linares, A. Stancu, P. Guionneau, and J. F. Létard, J. Appl. Phys. 106, 053515 (2009).

${ }^{41}$ M. Born and K. Huang, Dynamical Theory of Crystal Lattices (Oxford University Press, London, 1968).

${ }^{42}$ K. Boukheddaden and F. Varret, Hyperfine Interact. 72, 349 (1992).

${ }^{43}$ E. J. M. Vertelman, Ph.D. thesis, University of Groningen, 2009.

${ }^{44}$ H. Yun, T. Guodong, L. Fupei, H. Yanjun, and H. Mali, J. Alloys Compd. 438, 52 (2007).

${ }^{45}$ M. Sorai, M. Nakano, and Y. Miyazaki, Chem. Rev. 106, 976 (2006).

${ }^{46}$ M. Castro, J. A. Rodríguez-Velamazán, K. Boukheddaden, F. Varret, H. Tokoro, and S. Ohkoshi, EPL 79, 27007 (2007).

${ }^{47}$ S. Cobo, R. Fernández, L. Salmon, G. Molnár, and A. Bousseksou, Eur. J. Inorg. Chem. 2007(11), 1549 (2007); J. Luzón, M. Castro, E. J. M. Vertelman, R. Y. N. Gengler, P. J. van Koningsbruggen, O. Molodtsova, M. Knupfer, P. Rudolf, P. H. M. van Loosdrecht, and R. Broer, J. Phys. Chem. A 112, 5742 (2008).

${ }^{48}$ J. C. Lashley, M. F. Hundley, A. Migliori, J. L. Sarrao, P. G. Pagliuso, T. W. Darling, M. Jaime, J. C. Cooley, W. L. Hults, L. Morales, D. J. Thoma, J. L. Smith, J. Boerio-Goates, B. F. Woodfield, G. R. Stewart, R. A. Fisher, and N. E. Phillips, Cryogenics 43, 369 (2003). 